\title{
Fatal Rebleeding from a Dural Arteriovenous Malformation of the Posterior Fossa: case report with pathological examination
}

\author{
J. Max Findlay and Bruce W. Mielke
}

\begin{abstract}
A seventy-year-old woman suffered a fatal cerebellar rehemorrhage from a large venous aneurysm associated with a dural arteriovenous malformation (AVM) of the posterior fossa. The malformation, fed by branches of the right vertebral, occipital and middle meningeal arteries, had a nidus in the transverse sinus wall with a pedunculated extension reaching the pial surface of the adjacent cerebellum, from where the malformation drained exclusively into an aneurysmal cerebellar vein. There was no associated venous sinus obstruction. Histopathological examination of the venous sinuses, arteriovenous malformation and venous drainage is described and these findings as they relate to the pathogenesis of dural AVMs are discussed. Vascular malformations of the dura mater do not appear to be a single clinical or pathological entity. The serious risk of hemorrhage from a parenchymal venous aneurysm is emphasized.
\end{abstract}

\begin{abstract}
Résumé: Récidive fatale d'une hémorragie due a une malformation artérioveineuse de la fosse postérieure. À propos d'un cas soumis à l'examen anatomopathologique. Une femme âgée de soixante-dix ans a subi une récidive fatale d'une hémorragie cérébelleuse due à un gros anévrisme veineux associé à une malformation artérioveineuse durale (MAV) de la fosse postérieure. La malformation, alimentée par des rameaux des artères vertébrale, occipitale et méningée moyenne droites, avait un foyer dans la paroi du sinus transverse avec une extension pédiculée s'étendant jusqu'à la surface de la piemère du cervelet adjacent, d'où la malformation se drainait exclusivement dans une veine cérébelleuse anévrismale. Aucune obstruction du sinus veineux n'y était associée. Nous décrivons l'examen histopathologique des sinus veineux, de la malformation artério-veineuse et du drainage veineux et nous discutons de ces observations en relation à la pathogenèse des MAV durales. Les malformations vasculaires de la dure-mère ne semblent pas constituer une seule entité clinique ou anatomopathologique. Nous insistons sur la gravité du risque de l'hémorragie due à un anévrisme veineux parenchymateux.
\end{abstract}

Can. J. Neurol. Sci. 1994; $21: 67-71$

Dural arteriovenous malformations (AVMs) consist of an arteriovenous fistula located within dura, and while they can occur in any dural structure they are most often found near the transverse and sigmoid sinuses. Symptoms from dural AVMs in this location frequently consist of bruit, tinnitus and headache, but those lesions with leptomeningeal and parenchymal venous drainage can result in intracranial hemorrhage and a more dangerous natural course. In the patient to be described fatal rebleeding from a right posterior fossa dural AVM provided a rare opportunity for a complete pathological examination of this lesion and its most serious complication, parenchymal hemorrhage.

\section{Case Report}

A-70-year-old woman was admitted to hospital on October 27, 1992 for investigation of ataxia, vomiting and generalized weakness, several weeks in duration. Computed tomography revealed an apparent large right cerebellar hemorrhage and hydrocephalus. A contrast-enhancing structure was noted within the hematoma (Figure 1), and cerebral angiography demonstrated a right posterior fossa dural AVM, fed by branches from the right occipital and vertebral arteries, and the posterior branch of the right middle meningeal artery (Figures 2 and 3). There was no cerebral arterial contribution to the lesion. The malformation drained slowly and exclusively into cerebellar veins, the largest of which bore a large, irregular aneurysm embedded in the right cerebellar hemisphere. The adjacent venous sinuses were not obstructed. Following symptomatic improvement with the placement of a ventriculoperitoneal shunt an attempt was made to catheterize the feeding vessels for embolization, but this was unsuccessful. Further surgery was declined, and following several months of improvement, the patient suddenly collapsed and expired January 4, 1993.

From the Division of Neurosurgery (J.M.F.) and the Department of Laboratory Medicine and Pathology (B.W.M.), Division of Anatomical Pathology. University of Alberta. RECEIVED MAY 20, 1993. ACCEPTED IN FINAL FORM OCTOBER 1, 1993.

Reprint requests to: J. Max Findlay, M.D., Ph.D., F.R.C.S.C., Associate Professor, University of Alberta, Department of Surgery, 2D1.02 Mackenzie Health Sciences Centre, 8440 - 112 Street, Edmonton, Alberta, Canada T6G 2B7 


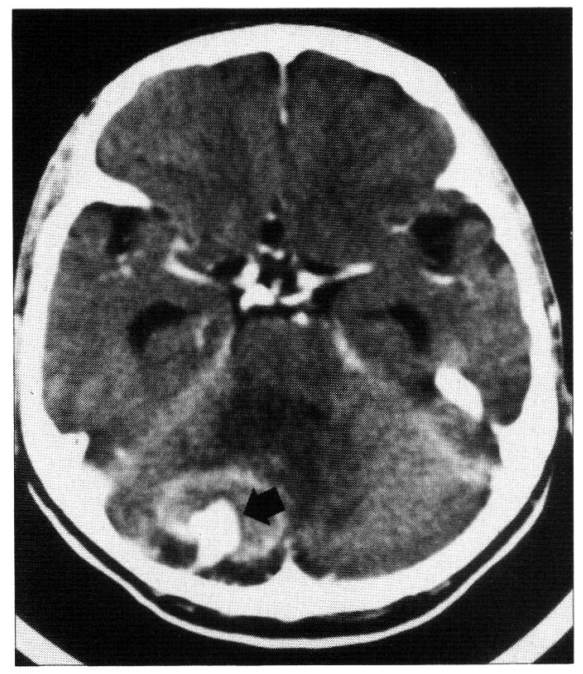

Figure 1: Computed tomographic scan showing a large right cerebellar hemisphere hemorrhage and associated hydrocephalus, and central enhancement within the clot (arrow') following intravenous contrast administration.

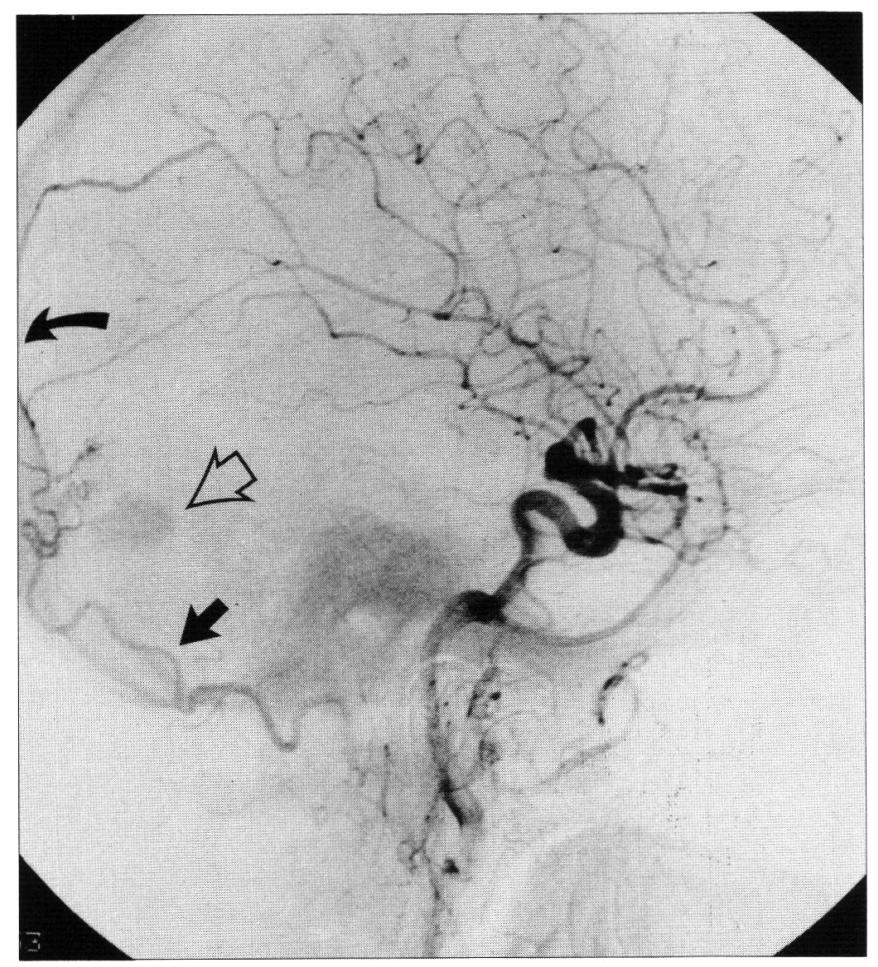

Figure 2: A right common carotid angiogram, lateral projection, shows a dural arteriovenous malformation in the right posterior fossa fed by the right occipital artery (straight arrow), an enlarged posterior branch of the right middle meningeal artery (curved arrow'). Faint, early opacification of a parenchymal venous aneurysm is seen (open arrow).

\section{Pathological Examination}

Gross findings included a massive recent hemorrhage within the anterior superior right cerebellar hemisphere which had ruptured into the fourth ventricle. The hemorrhage originated from near the vicinity of a large intracerebellar venous aneurysm which averaged $3.5 \times 2.5 \mathrm{~cm}$ (Figure 4). Cerebellar edema with tonsillar herniation accompanied the hemorrhage. Histologically, the wall of the large venous aneurysm con-

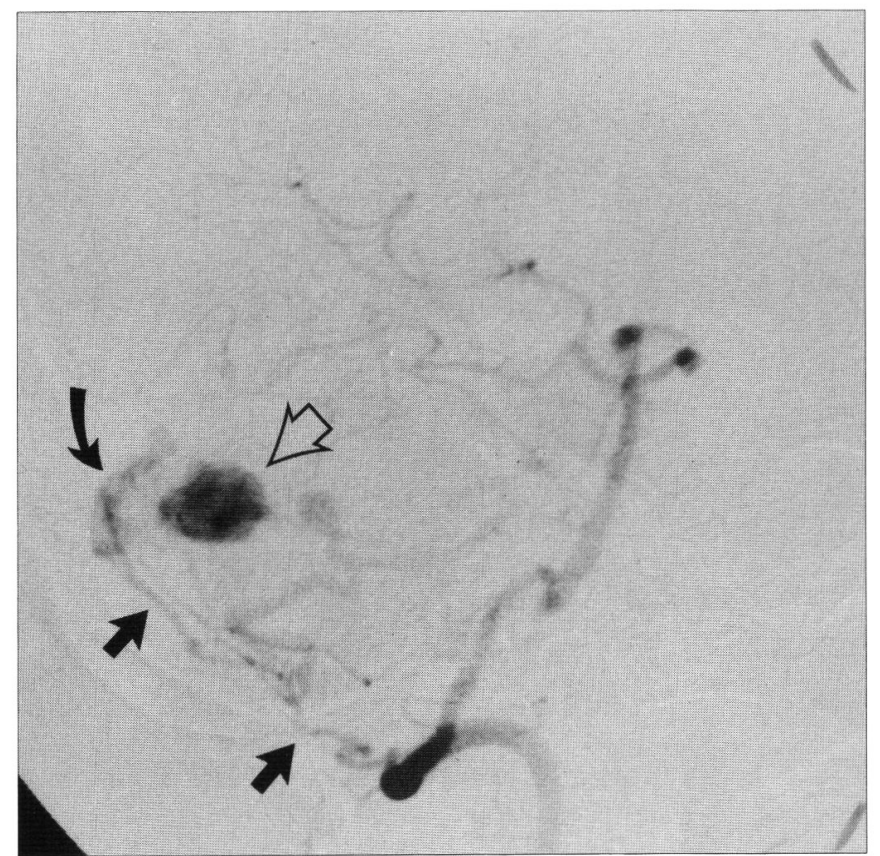

Figure 3: Right vertebral angiogram, oblique projection, shows a feeding artery arising from the horizontal segment of the vertebral artery (straight arrows) filling the dural arteriovenous malformation (curved arrow) which in turn drains into a large, irregular venous aneurysm embedded in the right cerebellar hemisphere (open arrow').

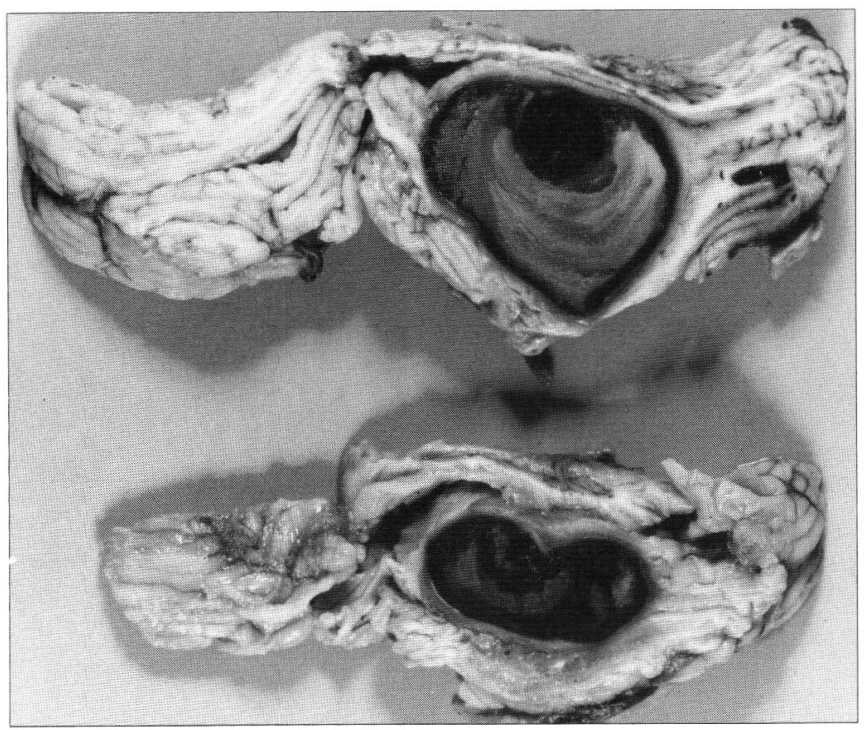

Figure 4: Coronal sections of cerebellum showing massive right hemispheric intra-parenchymal varix filled with laminated thrombus.

tained within the right cerebellar hemisphere showed some focal hemosiderin deposition and mild astroglial proliferation was present in the adjacent white matter. Several large ectatic venous channels with markedly tenuous walls were demonstrable overlying the cerebellar folia within the subarachnoid space of the right cerebellar hemisphere. Multiple abnormal, malformed veins and venules demonstrating focal mural fibrous thickening permeated the subjacent cortex and white matter (Figure 5). Widespread loss of Purkinje cells and focal depletion of the internal granule cell layer was seen in the cortex.

An abnormal collection of vascular channels also extended for a distance of approximately $1.5 \mathrm{~cm}$ along the margin of the posterior, right 


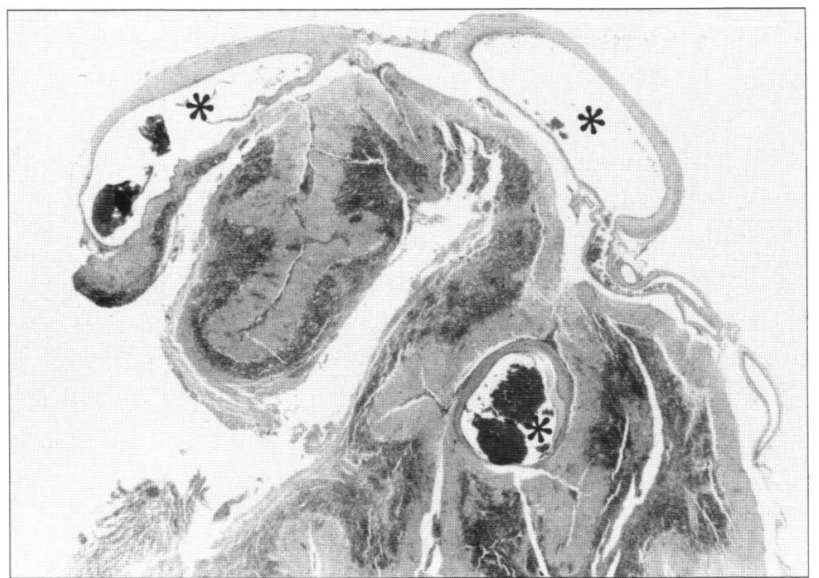

Figure 5: Lateral surface of right cerebellar hemisphere showing large dilated abnormal veins (asterisks), part of the arteriovenous malformation, within subarachnoid space over convolutions and within a sulcus. $(H \& E \operatorname{stain} x 24)$

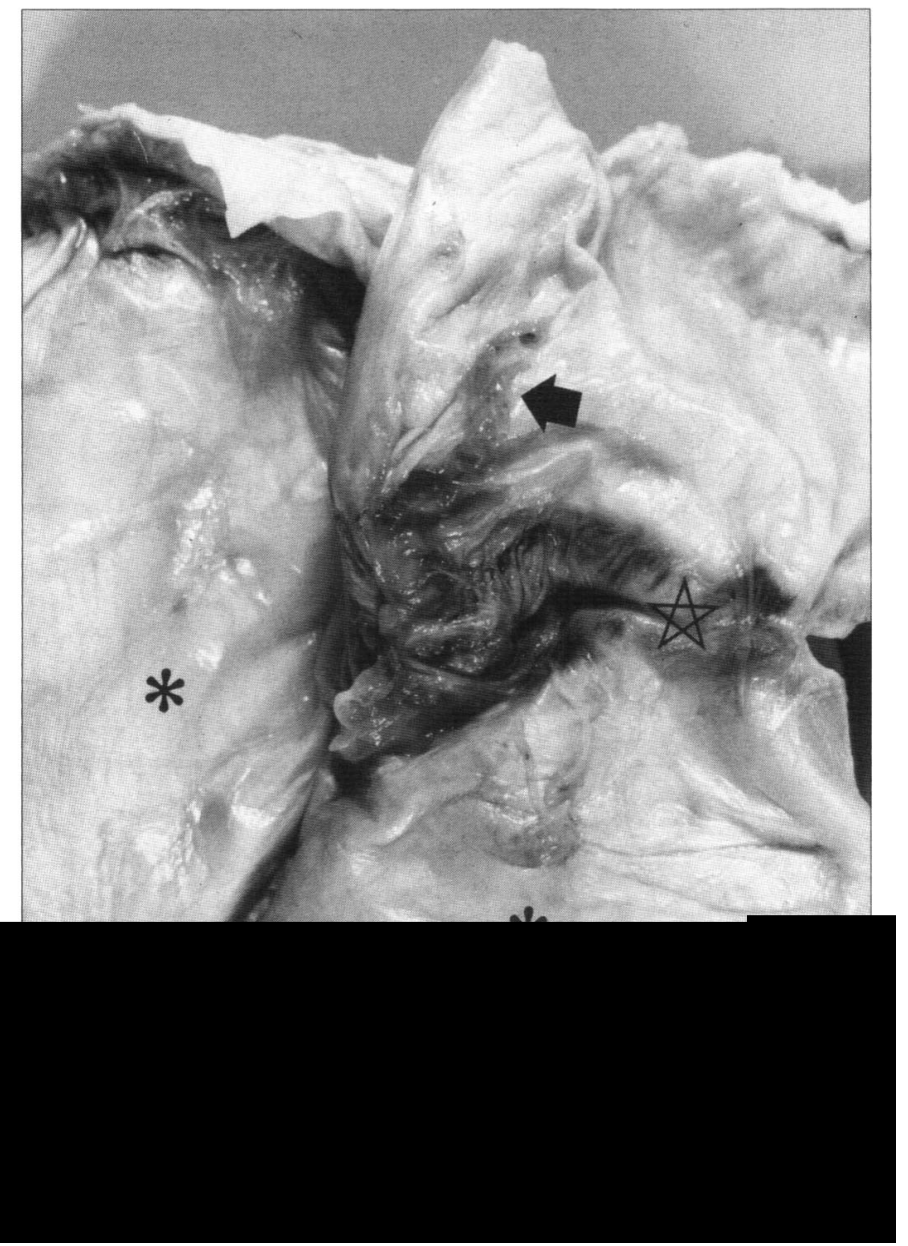

Figure 6: Inferior surface of tentorium cerebelli (asterisks) showing a partly subdural arteriovenous malformation over the torcula and right transverse sinus (star). Note prominent vein projecting from posterior surface of the lesion (arrow).

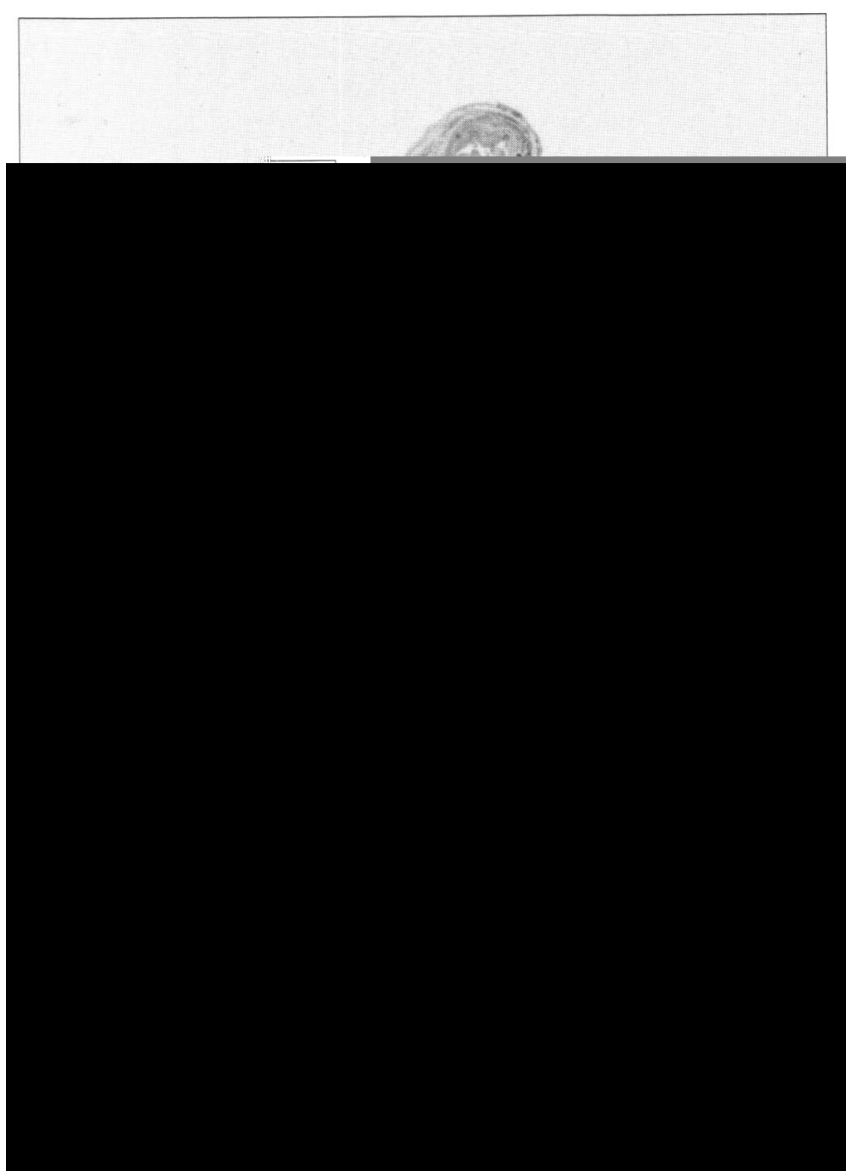

Figure 7: Arteriovenous malformation (AVM) composed of both arteries $(A)$ and ectatic veins $(V)$ located at margin of straight sinus $(S)$ just proximal to the torcula. (Elastic van Gieson x 12.)

transverse sinus, reaching the torcula and adjacent straight sinus (Figure 6). Sections from along the entire extent of this structure and including the adjacent sinuses were embedded for histologic examination. A malformation consisting of both arterial and venous components was demonstrable in this subdural location, but it also involved the dural walls of the adjacent venous sinuses (Figure 7). The venous component consisted of dilated vessels with alternately markedly thin or sclerotic walls. There was no evidence of hemosiderin accumulation or inflammation within the malformation. Multiple sections through both transverse and sigmoid sinuses did not reveal any evidence of recent or recanalized intraluminal thrombosis, and at no point was the arteriovenous malformation in continuity with a sinus lumen. No intimal thickening of the sinuses or condensation of mural elastica was present.

\section{Discussion}

The problem of dural AVMs has been examined in a number of reviews, ${ }^{1-6}$ and the following generalizations regarding these relatively rare lesions can be made. While dural AVMs can occur at any dural location, almost two-thirds are near the transverse and sigmoid sinuses, usually supplied by branches of the occipital, vertebral, and meningeal arteries. The location and venous outflow characteristics of dural AVMs determine their clinical features. ${ }^{5.7}$ Symptomatic posterior fossa dural AVMs most commonly present with pulsatile tinnitus, headache, and intracranial bruit due to the high venous flow near the middle 
ear. Less commonly, neighbouring venous congestion leads to local cerebellar, brainstem or cranial nerve deficits, while more severe, global venous obstruction and insufficiency results in increased intracranial pressure. Arteriovenous shunting in the malformation is usually into an adjacent dural sinus. Presentation with subdural, subarachnoid or intracerebral hemorrhage has been clearly associated with a component of venous outflow into pia-arachnoid and parenchymal veins. Dural AVMs that drain solely into cortical vein ${ }^{8}{ }^{8}$ as well as those with variceal or aneurysmal venous structures in the cortical outflow, have been particularly associated with intracranial bleeding. ${ }^{6}$ Although dural AVMs are rare, subarachnoid and intracerebral hemorrhage from these lesions occurs sufficiently often to warrant consideration of a dural AVM and selective external carotid angiography in cases of unexplained intracranial bleeding.

Houser and colleagues were the first to appreciate the relationship between dural AVMs of the posterior fossa and obstruction of adjacent dural venous sinuses, and to document that sinus occlusion sometimes precedes development of a dural AVM. ${ }^{9}$ This, along with the preponderance of dural AVMs discovered past middle age, led these authors to conclude that dural AVMs are acquired lesions. They speculated that arteriovenous shunting could result from arterioles recanalizing the venous thrombus reaching a patent segment of the sinus. A more recent variation of this theory proposed that sinus thrombosis, from whatever cause, results in engorgement of nearby sinus venous tributaries which rupture into adjacent dural arteries, creating a fistula. ${ }^{6}$ Direct arterial shunting into a dural sinus and local venous hypertension could then favour retrograde leptomeningeal venous drainage and varicose or aneurysmal dilatation of these channels. However, the occurrence of dural AVMs without dural sinus abnormalities, as in our patient, suggests that sinus obstruction is not part of the pathogenesis in every case.

Few pathological examinations of dural AVMs have been reported. Surgically excised specimens have contained large, thick-walled and irregular dural vessels, in combination with thrombosed or stenotic sinus channels. ${ }^{9-11}$ Graeb and Dolman have provided the only complete histopathological examination of a dural AVM, which was an extraordinary case of widespread, partially recanalized thrombotic occlusion of the superior sagittal sinus surrounded by multiple abnormal fistulous communications between abnormal extracerebral arteries and arterialized veins in the surrounding dura. ${ }^{12}$

Autopsy examination of our case enabled study of the dural AVM and adjacent brain. The blood supply to the malformation was typical of those in the transverse sigmoid sinus area, derived from branches of the occipital, vertebral and posterior meningeal arteries. A typical arteriovenous malformation was present involving the dural wall and overlying subdural space of the posterior margin of the transverse sinus, torcula and adjacent straight sinus. The lesion consisted of small arteries and considerably dilated venous vascular channels. Of interest was the fact that the malformation was not entirely intradural and also had a gross extension that reached and spread over the pial surface of the underlying right cerebellar hemisphere. Venous drainage was solely into parenchymal veins leading away from this extension, one of which had become markedly aneurysmal. The dural sinuses were normal.
The case reported here appears to be an example of a distinct variation of dural AVM, with findings different than described for dural AVMs in the few previous pathological examinations in the literature. Barnwell et al. have described the angiographic and clinical characteristics of a small subset of patients, similar to ours, extracted from their much larger series of typical dural AVMs with direct shunting into narrowed or obstructed major dural venous sinus. ${ }^{8}$ In the former seven patients the fistula was angiographically located in a sinus wall but outflow was only into cortical veins despite a patent dural sinus. Three of the patients in that report presented with intracranial hemorrhage, and all were treated successfully with either surgical coagulation or transvascular embolization of the lesion.

The pathogenesis for this type of dural AVM is clearly unrelated to a venous sinus abnormality, and the pathology of the lesion we encountered was typical of a congenital AVM. In previous reports and reviews the "aggressive" natural history of dural AVMs of any type with cortical venous drainage has been inferred from their hemorrhagic presentation; most lesions have subsequently been treated with either surgical excision, ${ }^{13}$ transarterial embolization, ${ }^{14}$ transvenous occlusion, ${ }^{15}$ radiation therapy, ${ }^{16}$ or a combination of these methods. The fatal rebleeding from the large venous aneurysm in our patient in whom the dural AVM was not eradicated emphasizes the true danger of this unique type of dural AVM.

\section{ACKNOWLEDGEMENTS}

The authors thank Dr. Paul McGann for making possible the autopsy examination, and appreciate Ms. Arlene MacLean's help in the preparation of this manuscript.

\section{REFERENCES}

1. Houser OW, Baker HL Jr, Rhoton A Jr, Okazaki H. Intracranial dural arteriovenous malformations. Radiology 1972; 105: 55-64.

2. Obrador S, Soto M, Silvela J. Clinical syndromes of arteriovenous malformations of the transverse-sigmoid sinus. J Neurol Neurosurg Psychiatry 1975; 38: 436-451.

3. Kuhner A, Krastel A, Stoll W. Arteriovenous malformations of the transverse dural sinus. J Neurosurg 1976; 45: 12-19.

4. Malik GM, Pearce JE, Ausman JI, Mehta B. Dural arteriovenous malformations and intracranial hemorrhage. Neurosurgery 1984; 15: 332-338.

5. Lasjaunias P, Ming C, Ter Brugge K, et al. Neurological manifestations of intracranial dural arteriovenous malformations. J Neurosurg 1986; 64: 724-730.

6. Awad IA, Little JR, Akrawi WP, Ahl J. Intracranial dural arteriovenous malformations: factors predisposing to an aggressive neurologic course. J Neurosurg 1990; 72: 839-850.

7. Vinuela F, Fox AJ, Pelz DM, Drake CG. Unusual clinical manifestations of dural arteriovenous malformations. J Neurosurg 1986; 64: 554-558.

8. Barnwell SL, Halbach VV, Dowd CF, et al. A variant of arteriovenous fistulas within the wall of dural sinuses. J Neurosurg 1991; 74: 199-204.

9. Houser OW, Campbell JK, Campbell RJ, Sundt TM Jr. Arteriovenous malformation affecting the transverse dural venous sinus - an acquired lesion. Mayo Clin Proc 1979; 54: $651-661$

10. Aminoff MJ. Vascular anomalies in the intracranial dura mater. Brain 1973; 96: 601-612.

11. Nishijima M, Takaku A, Endo S, et al. Etiological evaluation of dural arteriovenous malformations of the lateral and sigmoid sinuses based on histological examinations. J Neurosurg 1992; 76: $600-606$. 
12. Graeb DA, Dolman CL. Radiological and pathological aspects of dural arteriovenous fistulas. J Neurosurg 1986; 64: 962-967.

13. Sundt TM Jr, Piepgras DG. The surgical approach to arteriovenous malformations of the lateral and sigmoid dural sinuses. Neurosurgery 1983; 59: 32-39.

14. Vinuela FV, Debrun GM, Fox AJ, et al. Detachable calibrated-leak balloon for superselective angiography and embolization of dural arteriovenous malformations. J Neurosurg 1983; 58: 817 . 823.
15. Halbach VV, Higashida RT, Hieshima GB, et al. Transvenous embolization of dural fistulas involving the transverse and sigmoid sinuses. Am J Neuroradiol 1989; 10: 385-392.

16. Chandler HC Jr, Friedman WA. Successful radiosurgical treatment of a dural arteriovenous malformation: case report. Neurosurgery 1993; 33: 139-142. 